\title{
Vulnerability of rainfed maize crops in Mexico to climate change
}

\author{
Cecilia Conde ${ }^{1, *}$, Diana Liverman ${ }^{2}$, Margarita Flores $^{1}$, Rosa Ferrer $^{1}$, Raquel Araújo $^{1}$, \\ Edith Betancourt ${ }^{1}$, Gloria Villarreal ${ }^{1}$, Carlos Gay $^{3}$ \\ ${ }^{1}$ Centro de Ciencias de la Atmósíera, Universidad Nacional Autónoma de México, Ciudad Universitaria, \\ Circuito Exterior, CP 04510, México, D.F. México \\ ${ }^{2}$ Latin American Area Center, 1522 East Drachman, PO Box 21045, University of Arizona, Tucson, Arizona 85721, USA \\ ${ }^{3}$ Unidad de Cooperación y Convenios Internacionales, Instituto Nacional de Ecología, Avenida Revolución 1425 nivel 31 , \\ 01040, México, D.F. México
}

\begin{abstract}
The impacts of a potential climate change on rainfed maize crops in Mexico are analyzed. For that purpose, baseline scenarios based on current climate conditions and their relation with maize crop development were created. Climate change scenarios were further developed and the crop vulnerability under each scenario was assessed. Two methods were used to quantify vulnerability. In the first place, maps describing the suitability for crop production according to climate conditions were produced. The differences between the baseline and the climate change scenarios allowed for estimating the area of the country likely to be positively or negatively affected. Secondly, the CERES-Maize model was applied to estimate rainfed maize crop yields at 7 sites in Mexico under the baseline and climate change scenarios. Adaptive measures were proposed and their feasibility was assessed on the basis of a simple cost-benefit analysis.
\end{abstract}

KEY WORDS: Agriculture - Rainfed maize crops - Climate change - Vulnerability - Adaptation . CERES-Maize model

\section{INTRODUCTION}

The Mexico Climate Change Country Study addresses the vulnerability of the country to a potential climate change with regard to different sectors (forests, agriculture, soils, coastal areas, human settlements, energy and industry).

The agricultural sector assessment focusses on the vulnerability of spring-fall cycle rainfed maize crops under the scenarios developed by the corresponding task group within the framework of the Country Study.

Maize is grown throughout the country. This crop is heavily dependent on climate conditions. The low yields and the large area damaged every year indicate that this crop largely is not grown for large-scale com-

\footnotetext{
•E-mail: conde@servidor.unam.mx
}

mercialization, and that a cost-benefit relation of $1: 3$ can hardly be achieved (INEGI 1994).

On the other hand, the fact that this crop is grown in areas that may not be suitable, either with regard to climate conditions (Fig. 1) or soils and slopes, may explain the high crop losses and low yields-lower than $1 \mathrm{tha} \mathrm{ha}^{-1}$-in over $50 \%$ of the total area planted.

\section{METHODS}

Baseline climate scenarios were created based on daily and/or monthly temperature, precipitation and sunshine duration data provided by the Servicio Meteorológico Nacional. These data were available in the CLICOM system, in monthly reports or in the database produced by Arthur Douglas (Magaña 1994), which was processed and provided for the 


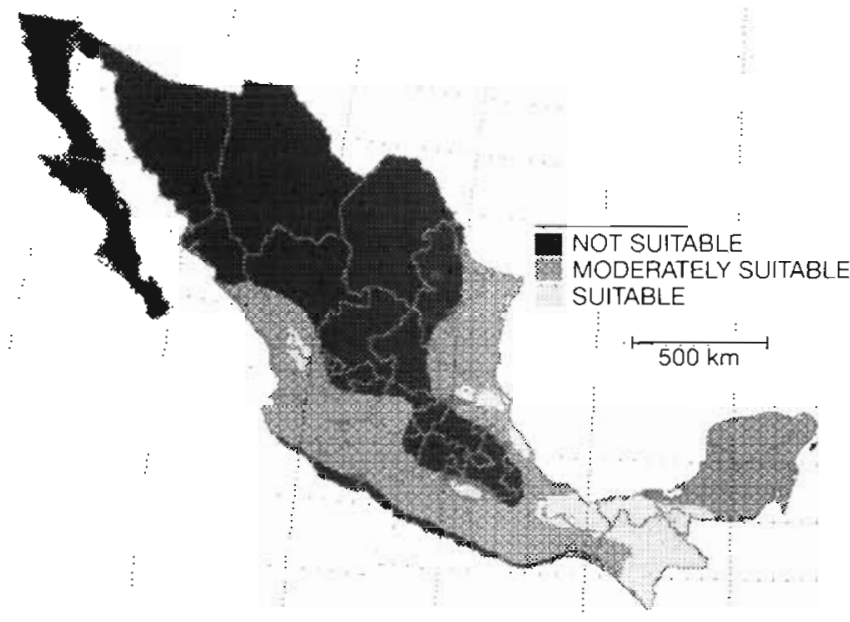

Fig. 1 Potentially suitable zones for rainfed maize crops in Mexico. Basseline scenario

Country Study vulnerability analyses by the climate scenario task group.

Missing daily data were generated with the WFORM program (Rosenzweig \& Jones 1990) on the basis of monthly averages.
Two types of climate change scenarios were considered (Conde et al. 1995). Scenarios based on arbitrary temperature increments $\left(+2^{\circ} \mathrm{C},+4^{\circ} \mathrm{C}\right)$ combined with changes in precipitation ( $\pm 20 \%$ ) were first applied, followed by scenarios derived from the CCCM (Canadian Climate Center Model) and GFDL-R30 (Geophysical Fluids Dynamics Laboratory) general circulation models (GCMs), using their $2 \times \mathrm{CO}_{2}$ minus $1 \times \mathrm{CO}_{2}$ outputs.

The identification of potentially suitable zones for maize production in the country was performed under baseline and climate change scenarios. These scenarios were also used in the CERES-Maize model for the assessment of maize yield variations ( $\mathrm{t} \mathrm{ha}{ }^{-1}$ ) at sites within 4 major rainfed maize growing states in Mexico (Fig. 2, Table 1), A reduction in the duration of the maize growth cycle was observed in all cases.

\section{RESULTS}

\subsection{Climate change vulnerability}

Climate change vulnerability was assessed by estimating changes in the area of suitable, moderately suitable and non-suitable zones for maize production.

Table 1. Location, altitude and time periods for the selected study sites

\begin{tabular}{|c|c|c|c|c|c|}
\hline Site & State & $\begin{array}{l}\text { Latitude } \\
\text { (N) }\end{array}$ & $\begin{array}{l}\text { Longitude } \\
\text { (W) }\end{array}$ & $\begin{array}{c}\text { Altitude (m } \\
\text { above sea level) }\end{array}$ & Years \\
\hline Atlacomulco (Atla) & México & $19^{\circ} 49^{\prime}$ & $99^{\circ} 42^{\prime}$ & 2520 & $1961-1974$ \\
\hline Izúcar (Izuc) & Puebla & $18^{\circ} 37^{\prime}$ & $98^{\circ} 28^{\prime}$ & 1285 & $1974-1989$ \\
\hline Ixcamilpa (Ixca) & Puebla & $18^{\circ} 02^{\prime}$ & $98^{\circ} 42^{\prime}$ & 806 & $1975-1990$ \\
\hline Coatepec (Coat) & Veracruz & $19^{\circ} 32^{\prime}$ & $96^{\circ} 55^{\prime}$ & 1110 & $1967-1985$ \\
\hline Tuxpan (Tuxp) & Veracruz & $20^{\circ} 57^{\prime}$ & $97^{\circ} 24^{\prime}$ & 25 & $1971-1988$ \\
\hline La Huerta (Huer) & Jalisco & $19^{\circ} 22^{\prime}$ & $105^{\circ} 0^{\prime}$ & 28 & $1962-1986$ \\
\hline Magdalena (Magd) & Jalisco & $20^{\circ} 55^{\prime}$ & $103^{\circ} 58^{\prime}$ & 1359 & $1961-1988$ \\
\hline
\end{tabular}

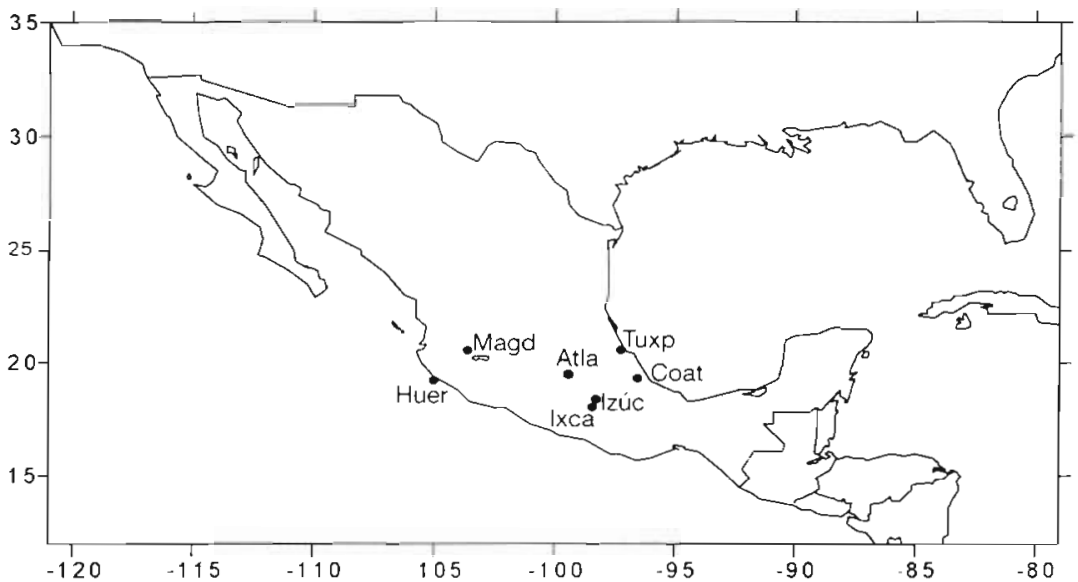

Fig. 2. Location of the 7 study sites within 4 Mexican states where the CERESMaize model was applied. The abbreviations stand for the first 4 letters of the site name (see Table 1) 


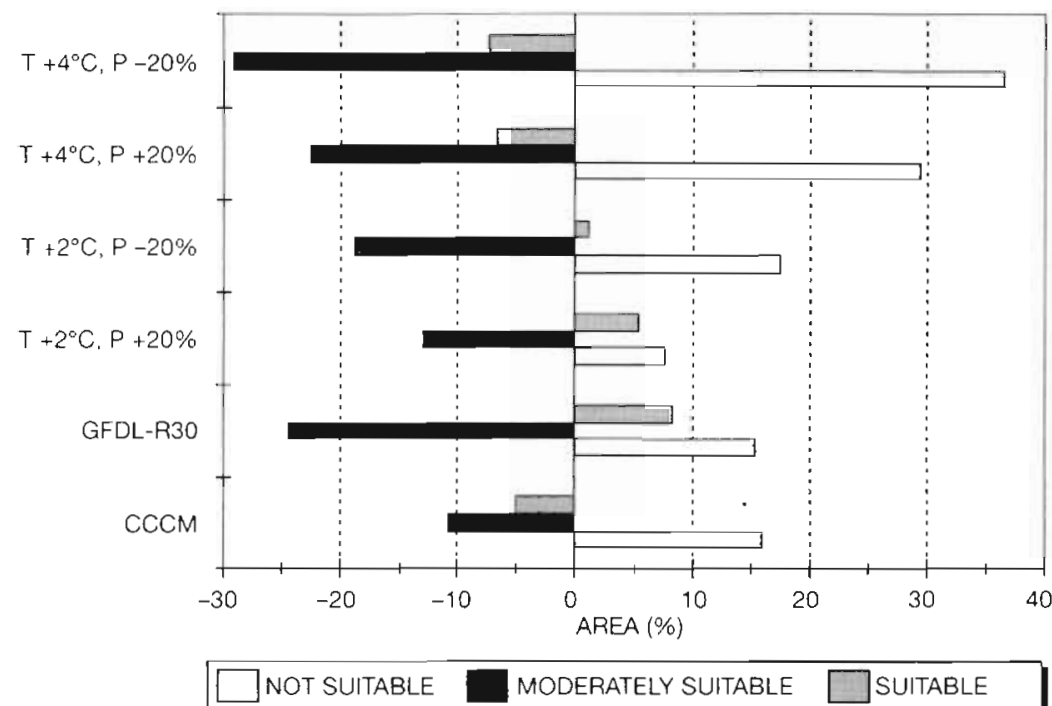

Fig. 3. Percentage differences in the relative area occupied by non-suitable, moderately suitable and suitable land between baseline and climate change scenarios

in area by $8 \%$. The most affected regions would be the central and northern parts of the country. Under changes of $+2^{\circ} \mathrm{C}$ and $-20 \%$, an $18 \%$ increase in the area of non-suitable zones would occur. In the case of the first scenario, the non-suitable zones would increase to the detriment of the moderately suitable zones, while in the second case they would increase as a result of a reduction in moderately suitable and suitable zones (Fig. 3). The moderately suitable zones would thus be the most vulnerable. Given a temperature increment of $+4^{\circ} \mathrm{C}$ and the same precipitation changes $( \pm 20 \%)$, the increase in the non-suitable area would be even more dramatic (20 to $37 \%)$.

CERES-Maize model simulations (Figs. 4 \& 5) under incremental temperature and precipitation scenarios

under the climate change scenario with respect to the baseline conditions. A change was deemed positive when there was an improvement in the suitability of the area (e.g. from moderately suitable to suitable), while a change in the opposite direction was defined as negative. Variations in non-suitable zones are particularly noted, since an increase in those areas was estimated to occur under all climate change scenarios.

The potential changes under incremental scenarios were first analyzed. Results indicate that, given changes in temperature and precipitation of $+2^{\circ} \mathrm{C}$ and $+20 \%$ respectively, non-suitable zones would increase

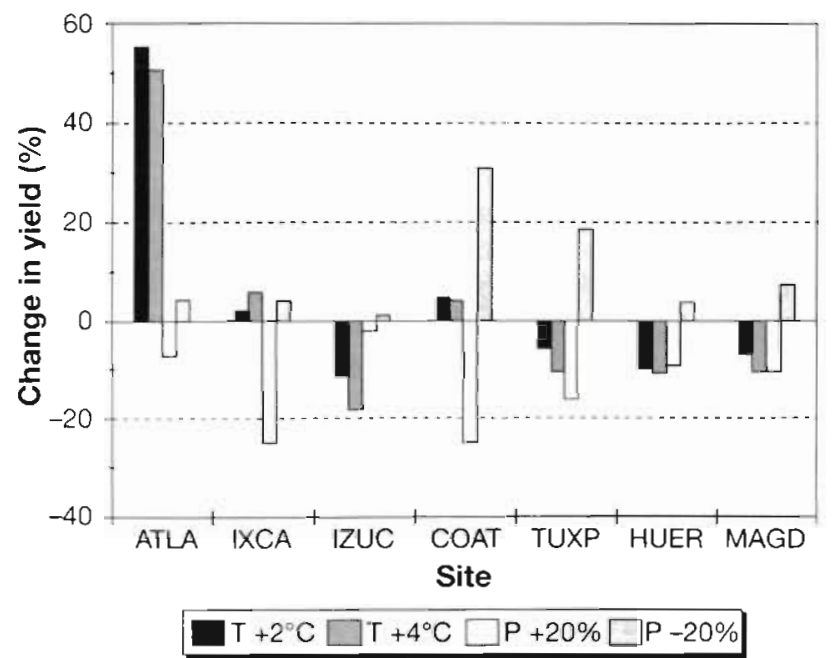

Fig. 4. Results from the vulnerability assessment under temperature or precipitation incremental scenarios resulted in favorable yield changes in the case of Atlacomulco. This is due to the fact that crops in this region are often affected by frost. Thus, any increase in temperature is likely to have a positive effect independently from other potential changes in precipitation or from the possible physiological effects of carbon dioxide doubling. It is worth mentioning that the model had to be adjusted for the study site conditions in order to obtain the genetic coefficients (which are dependent on climate parameters), since the varieties handled by the model did not appropriately simulate maize phenology and observed yields.

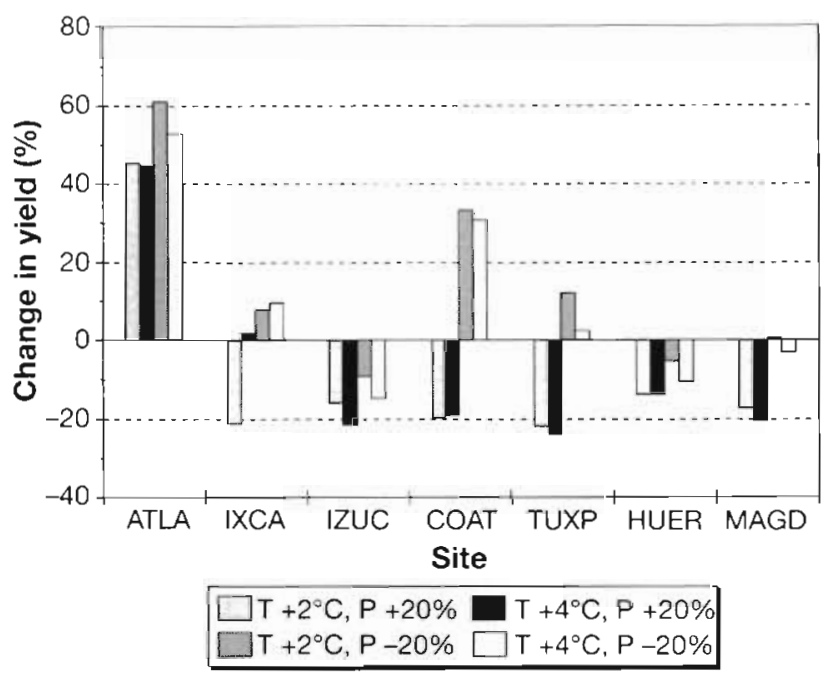

Fig. 5. Results from the vulnerability assessment under combined temperature and precipitation incremental scenarios 


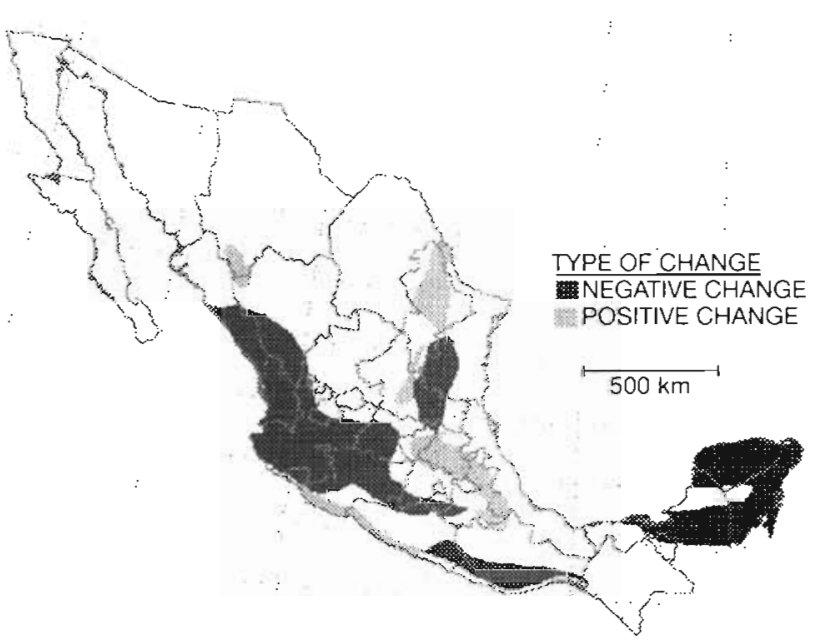

Fig. 6. Areas of Mexico vulnerable to climate change under the CCCM-derived scenario

On the other hand, the adverse effect that a $20 \%$ increase in precipitation was found to have at all sites is remarkable. This could be related to a decrease in soil nutrient availability, which resulted in an increase in nitrogen stress as observed in the CERES-Maize model outputs.

Vulnerability under the scenarios developed with the GCMs was further analyzed. Average temperature increases of 2 to $3^{\circ} \mathrm{C}$ for the country as well as precipitation decreases are estimated by the CCCM. The area negatively affected as regards maize production would be increased under these conditions (Fig. 3), mainly as a result of a reduction in the moderately suitable zones. The total area negatively affected for rainfed maize

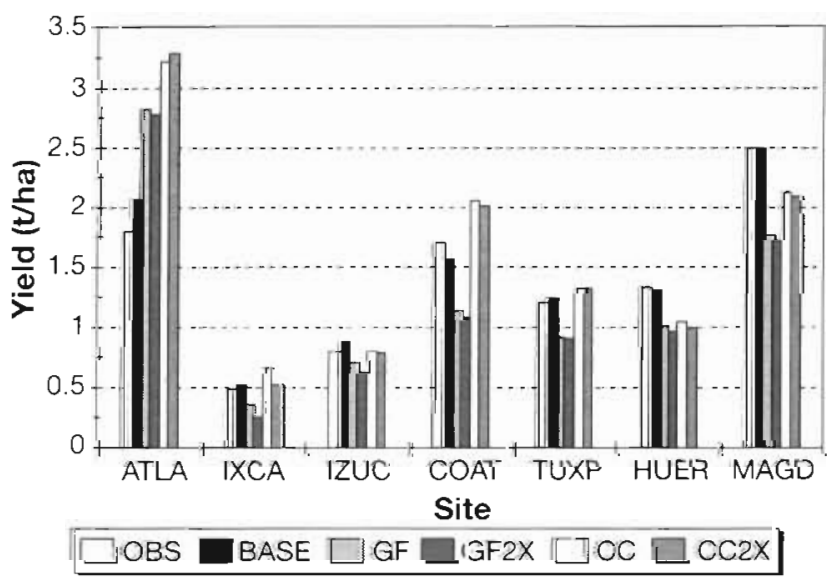

Fig. 7. Observed and simulated yields under the baseline and climate change scenarios projected by the CCCM $(\mathrm{CC})$ and GFDL (GF) models, with and without physiological effects of $2 \times \mathrm{CO}_{2}$

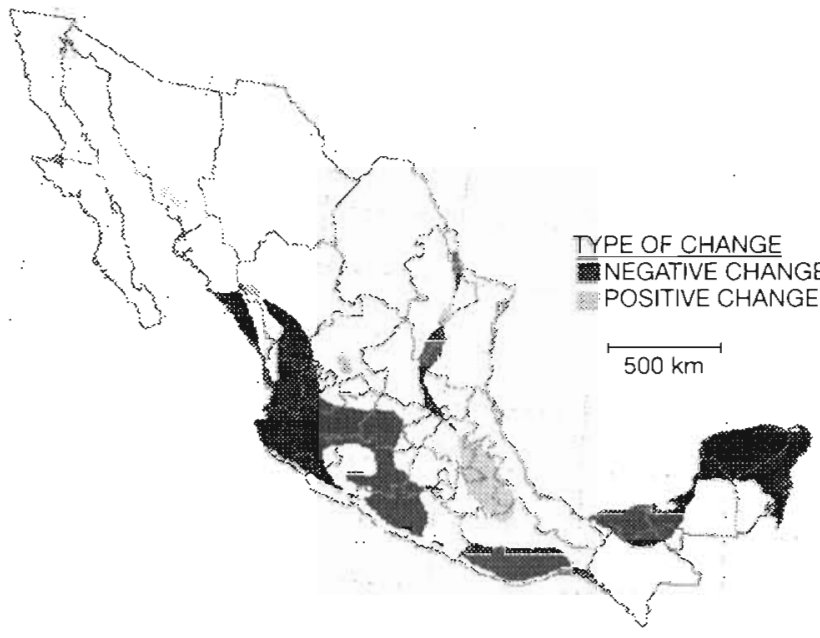

Fig. 8. Areas of Mexico vulnerable to climate change under the GFDL-R30 model derived scenario

production in the country would be about $429180 \mathrm{~km}^{2}$ (Fig. 6).

The physiological effects of a carbon dioxide doubling (555 ppm) were also assessed with CERES-Maize under both GCM scenarios. The results are displayed on Fig. 7 as $\mathrm{CC} 2 \times$ and GF2x.

A shift in the occurrence of the summer drought at sites in the central and western parts of the country was estimated by CERES-Maize under climate change scenarios. The minimum precipitation value is estimated to occur 1 mo in advance (between the 2 maximum values) during the rainy season.

Under the conditions projected by the CCCM the results at the 7 study sites are variable. The positive effect of climate change both at Atlacomulco and at the sites in Veracruz is visible (Fig. 7).

The GFDL-R30 model estimated average temperature increases of 3 to $5^{\circ} \mathrm{C}$-higher than those estimated by the CCCM-and positive changes in precipitation. The proportion of maize-planting area that would be negatively affected under the conditions of this scenario is $22 \%$ (Fig. 8). Yields estimated by CERES-Maize decreased at all sites under this scenario, except for Atlacomulco (Fig. 7).

\subsection{Adaptation as evaluated by the CERES-Maize model}

Several adaptive measures were analyzed based on the CERES-Maize outputs. Those resulting in significant yields were selected and classified according to their implementation cust. An increased application of fertilizer (urea) was deemed the most effective mea- 


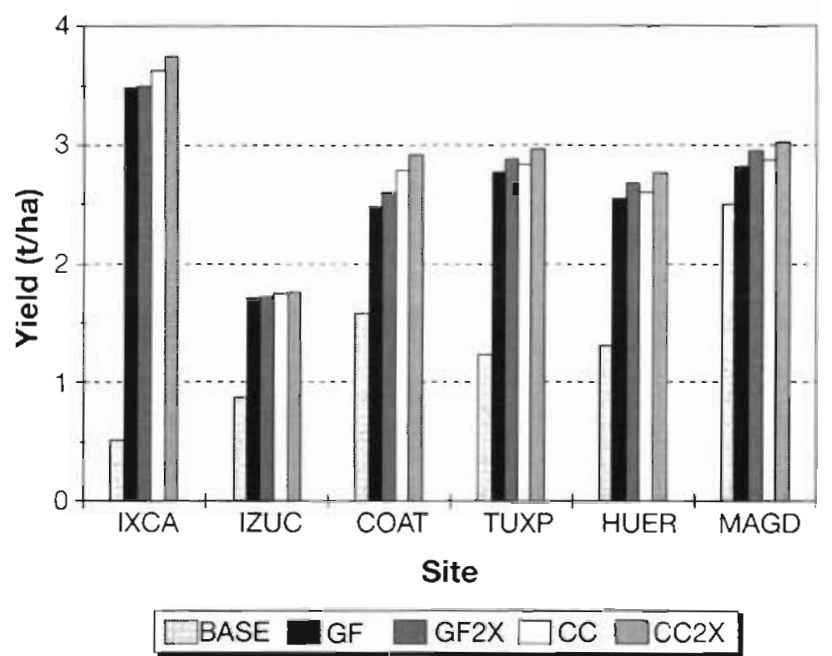

Fig. 9. Potential yields if fertilization is used as an adaptive measure for all study sites

sure at all sites (Fig. 9), with or without consideration of the physiological effects of $\mathrm{CO}_{2}$ doubling. Other adaptive measures combined with fertilization (e.g. change in planting date, change in cultivar) were also tested. Remarkably higher yields as compared to current production were obtained with changes in cultivars. However, the implementation of this measure is not feasible at all sites due to its high cost and to the economic situation of the farmers.

\subsection{Cost-benefit analysis}

A very simple cost-benefit analysis, under a hypothesis of zero inflation, was carried out in order to develop a basic economic scenario for assessing the feasibility of the proposed adaptive measures.
The potential increase in production costs as a result of the implementation of adaptive measures to reduce climate change impact was assessed. The costs used were those reported in the Paquete Tecnológico del Cultivo de Maíz (O. Fernández-Marroquín pers. comm.) for improving maize production at sites with yields of $0.5,1.5$ and $2.0 \mathrm{tha}^{-1}$. Prices of the required inputs correspond to 1994. A liberalization policy for maize price will be in effect in Mexico in the next century as a result of the implementation of the North American Free Trade Agreement (NAFTA) subscribed to by Mexico, the USA and Canada. The potential impact of this policy was also assessed.

Results of the analysis indicate that this an increased application of fertilizer would have a positive effect at all sites, provided that maize subsidies are not discontinued. Results for Puebla and Veracruz are displayed in Fig. 10, and those for Jalisco in Fig. 11.

Under a non-subsidy policy, however, the application of this adaptive measure would become unfeasible due to the high production costs involved, since profits would be reduced and losses could even occur (Figs. $12 \& 13$ ).

\section{DISCUSSION AND CONCLUSIONS}

It is considered that, under the prevailing situation, maize crops in Mexico are highly vulnerable both to the impact of extreme climatic events (droughts and floods) and to a potential climate change. This can be observed on the basis of the maps describing suitability for maize production which were generated during this study.

The CERES-Maize model is useful for simulating both current yields as well as projected yields under a global warming condition. It also enables the detailed analysis
Fig. 10. Cost-benefit analysis for sites in Puebla and Veracruz, assuming subsidies on maize price. The adaptation measure is an increased application of fertilizer

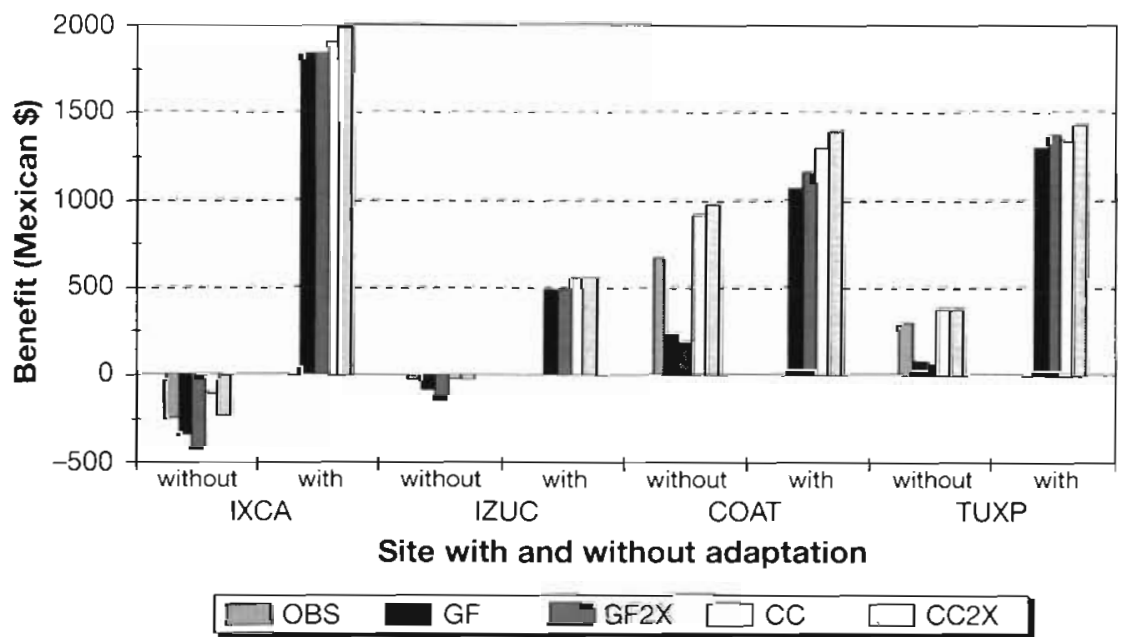




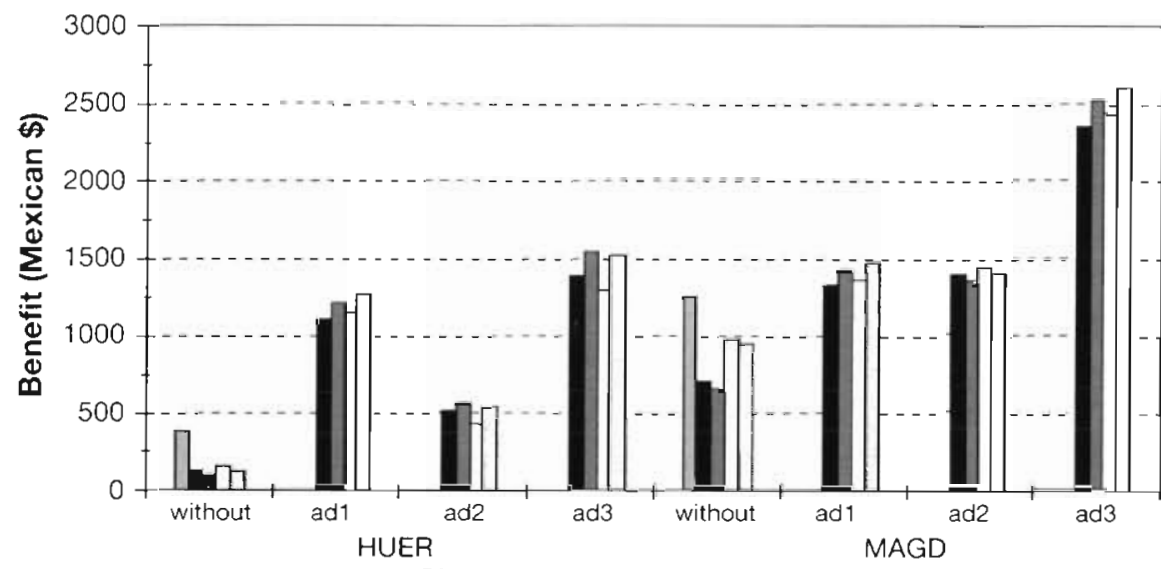

Site with and without adaptation

$\square$ OBS GF GF2X $\square$ CC $\square$ CC2X

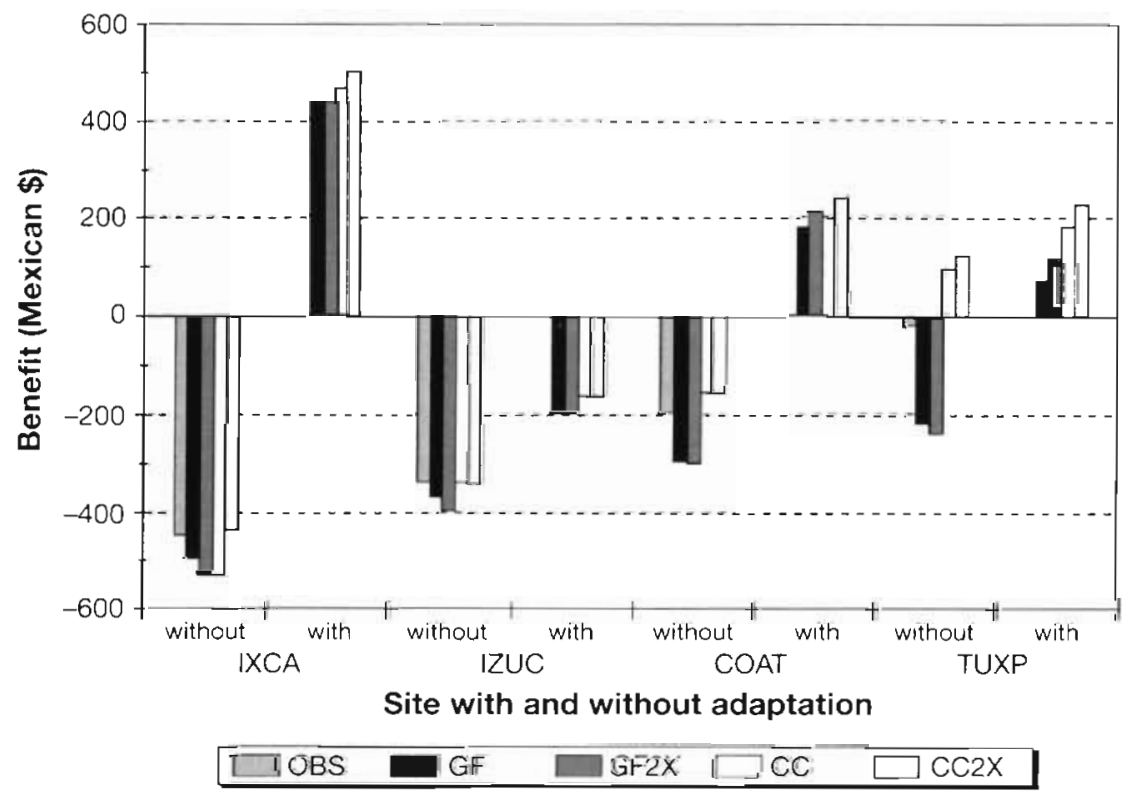

Fig. 11. Cost-benefit analysis for sites in Jalisco, assuming subsidies on maize price. ad 1: increase in fertilizer; ad2: changes in sowing date and in maize variety; ad3: as in ad2 with an increase in fertilizer
Fig. 12. Cost-benefit analysis for sites in Puebla and Veracruz, assuming maize price liberalization. The adaptation measure is an increased application of fertilizer of crop development stages, thus allowing the effect of nitrogen or water deficiencies to be estimated.

However, due to the complexity and frequent lack of climate, soil, crop phenology and historical yield data for the study sites, it may be necessary to take more general approaches, at the cost of reducing the reliability of results. Unfortunately the performance of the cultivars that are currently being used in Mexico cannot be well reproduced using the CERES-Maize model.

Despite this, the model results obtained during this study provided insight into current maize production conditions in Mexico and allowed an assessment of the possible impacts of future climate changes. An important conclusion of this study is that climate change would not necessarily have a negative impact on maize crops, particularly in the high altitude regions of Mexico. This result should be further analyzed in relation to studies on potential increase in soil erosion, which are also being performed within the framework of the Mexico Country Study.

Fertilization is proposed as a measure for adapting to climate change, although it would not be economically feasible at all study sites. The feasibility of applying this measure would be further reduced if subsidies for maize production were discontinued. Agricultural production in Mexico would likely be strongly impacted, even before being exposed to the effects of climate change. In any case, the potential occurrence of global warming calls for the urgent design of national strategies to respond to future climate changes in accordance with the economic policies of the country. 
Fig. 13. Cost-benefit analysis for sites in Jalisco, assuming no subsidies on maize price. With adaptation measures ad1, ad2, and ad3 as in Fig. 11

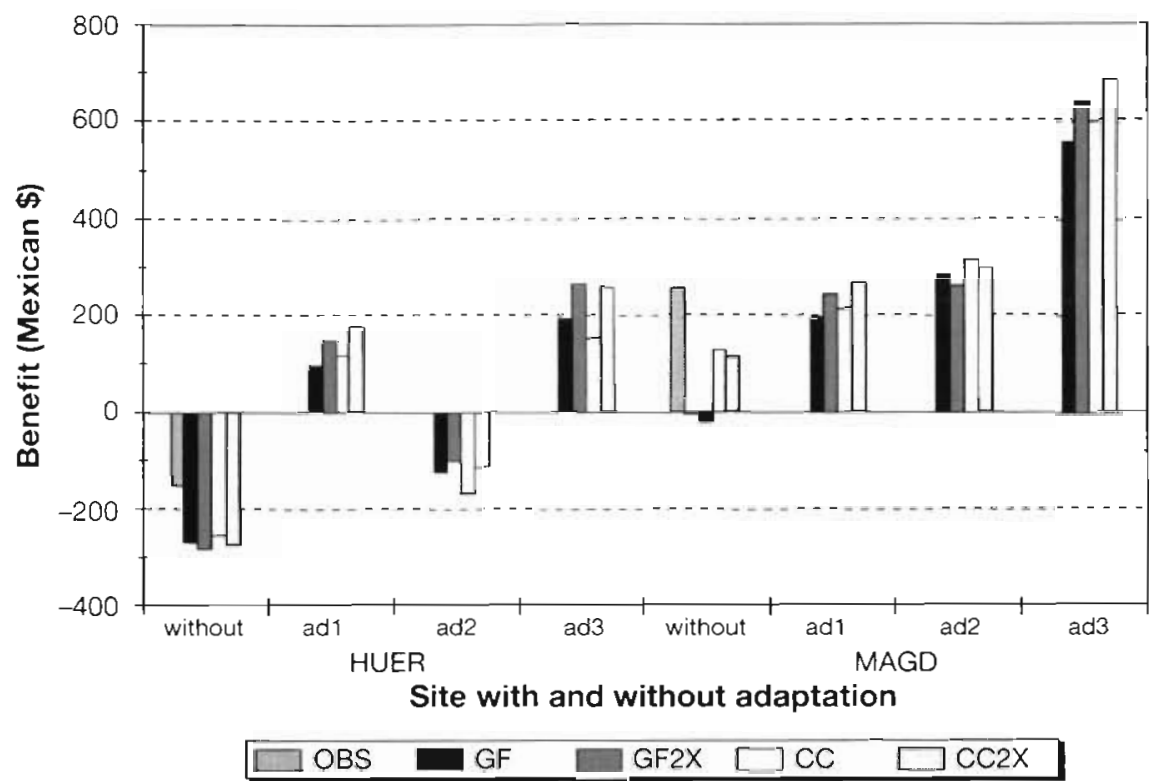

INEGI (Instituto Nacional de Estadística, Geografía e Informática) (1994) Estados Unidos Mexicanos. Resultados definitivos. VII censo agrícola-ganadero. Aguascalientes

Magana $V$ (1994) A strategy to determine regional climate change. México ante el cambio climático. Memorias del Primer Taller de Estudio de País: México. Instituto Nacional de Ecologia, México (eds). US Country Studies Program and Universidad Nacional Autónoma de México, Cuernavaca, p 45-51

Rosenzweig C, Jones J (1990) Climate change crop modeling study. Handbook. International Climate Change and Crop Modeling Workshop, 28 January-2 February 1990, Washington, DC. US Environmental Protection Agency, Office of Policy, Planning and Evaluation and US Agency for International Development S\&T/AGR/RNRM, Washington, DC 